\section{New products and focus on surgery equipment and oral health}

\section{MORE EFFECTIVE THAN STRING FLOSS}

The Waterpik Water Flosser - formerly the Waterpik dental water jet - supports professional recommendations to patients who do not like to floss.

Recent Waterpik research showed that people are often confused by the terms 'oral irrigator' or 'dental water jet', and do not understand how it fits into their oral hygiene routine. Waterpik's flagship oral care product, the Waterpik Water Flosser, is an easier and more effective alternative to traditional string floss.

Laboratory tests conducted by Waterpik showed that the Waterpik Water Flosser removed 99.9\% of plaque biofilm from treated areas in three seconds and up to two times as effective as string floss in reducing gingival bleeding after 14 days. The new Plaque Seeker Tip is designed to help remove even more stubborn plaque biofilm from hard to reach areas.

Reader response number 50

\section{SPECIALIST TRAINING CENTRE}

The Advanced Dental Training Centre in Oxford provides any or all of the following: bespoke planning for the course or lecture to ensure optimum levels of support; good natural light; a lecture theatre with audio-visual link to a clinical suite so that live surgery may be

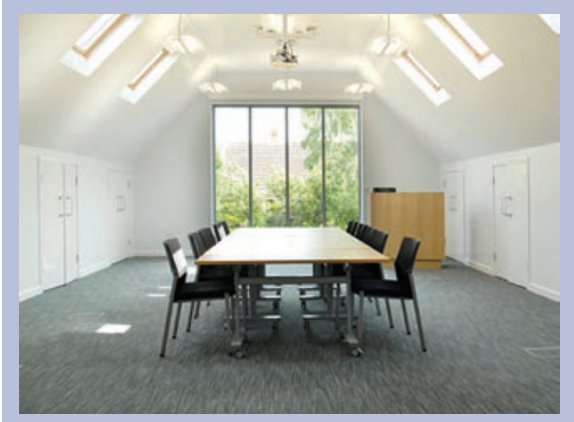

observed; dental laboratory facilities; 3D CBCT digital imaging; best practice HDU to meet HTM 01-05; sockets positioned for courses; air conditioning; easy access/free parking/good public transport links; a wide choice of menu options and a relaxed atmosphere.

Dentist and implant specialist Maria Hardman, who conceived the design brief for the training centre, runs a number of her own courses and as part of the service for those who wish to use the facilities at the Advanced Dental Training Centre, will provide guidance on structuring and running courses, lectures and seminars.

Rates for hiring the Lecture Theatre start from £200.

Reader response number 51

\title{
QUALITY FINANCIAL ADVICE FOR DENTISTS
}

The money4dentists team uses their outstanding knowledge and experience to provide dental professionals with specialist independent financial advice.

Money4dentists provide consistently reliable strategies for minimising tax by maximising income tax allowances, and in many instances reducing income tax liabilities to zero, mitigating Stamp Duty Land Tax. They can also advise on tax efficient saving plans and methods to safeguard the financial future of dependants and children, along with investment and pension planning.

\section{EDUCATION PROGRAMMES TO MAKE YOU SMILE}

Dental education provider Smile-on has recently boosted their comprehensive selection of programmes with new additions.

As an extension of the first three popular modules, Communication in Dentistry Modules 4, 5 and 6 will teach dental professionals how to further develop their communication skills with colleagues to reduce stress and create a positive environment in which to learn and work.

DNNET II has been designed to help training dental nurses studying for the National Certificate or NVQ level 3 in Oral Health Care Dental Nursing and as an update for established nurses.

Smile-on's online Core CPD platform allows individuals to plan and manage their CPD in core topic areas against the GDC's requirements. The platform also provides e-learning content, whereby the majority of the CPD is delivered directly from the platform.

2010 saw the team at Smileon celebrate its tenth anniversary of providing dental professionals with convenient ways to meet their CPD requirements.

Reader response number 52

Money4dentists will help you identify your objectives and priorities and guide you towards a practical strategy to achieve your goals. They are regulated by the Financial Authority and have been providing quality independent advice to UK dentists for generations.

Reader response number 53 


\section{EQUIPMENT TO ACCOMMODATE ALL YOUR NEEDS}

The A-Dec range of Clark Dental equipment is an experience in synergy: while optimising operator access and enhancing patient comfort, it provides your team with efficiency and flexibility at the same time.

The range offers equipment packages to suit all budgets. The A-Dec 500 accommodates every working position, offering traditional, continental or rear delivery; it is an ambidextrous unit and extremely flexible for

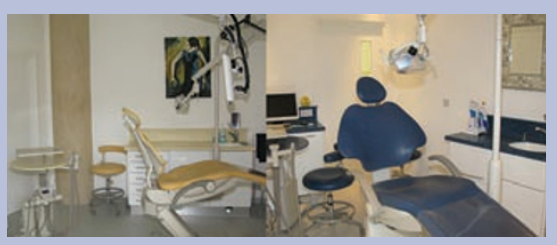

superb ergonomics. The A-Dec Radius series has practically unlimited positioning for the entire dental team. It can accommodate your needs whether you need a cuspidor or assistant's arm, continental or traditional, dental light or monitor mount.

The A-Dec 200 is a complete mid-level solution. With a robust design and small footprint, it is ideal for maximising space or creating a clean, contemporary environment. It is available in both left and right-handed versions. The A-Dec Performer is designed to provide the same reliability and patient comfort as other units in the range and saves you money without compromising on quality.

Reader response number 54

\section{ENJOY A SONIC SENSATION}

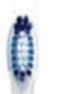

-B is launching a new sonic powered toothbrush, the Oral-B Pulsonic SmartSeries with Smartf Guide. This may come as a surprise to some, as brushes with an

- oscillating-rotating action have been independently acclaimed. However, some people prefer physically employing a brushing action themselves and the sensa-

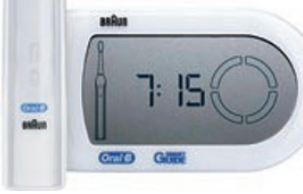

tion of a sonic product.

The Oral-B Pulsonic has a five-speed brushing action (clean, sensitive, massage, extended clean and polish) and offers 31,000 vibrations. Oral-B has also configured the bristles to maximise plaque removal.

Like the Triumph, the Oral-B Pulsonic contains a microchip in the handle that communicates information to the user via a wireless remote display, the 'SmartGuide'. This encourages patients to adhere to the universally recommended brushing time of two minutes. It also contains a quadrant timer, prompting patients to pay equal attention to all areas of the mouth.

Reader response number 55

\section{FIGHT SURGERY INFECTION WITH MIKE}

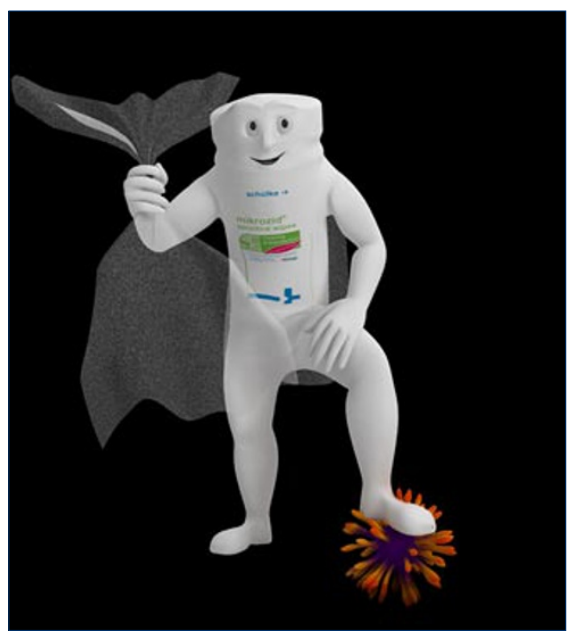

Schülke, the dental surgery infection control product manufacturer, has launched a new online game to help raise awareness of surface infection control.

With the help of Schülke's mascot for surgery surface disinfection, 'Mike' Mikrozid, dental professionals are invited to try their hand at ridding their surgery of the infective invaders using products from the mikrozid range as their weapons of choice.

Using the arrow keys on the keyboard to move around the virtual surgery and the space bar to kill invading bugs, dental professionals of all ages are sure to enjoy this light hearted and educational game.

The mikrozid range from Schülke includes well known names such as mikrozid AF, mikrozid sensitive and terralin protect.

Reader response number 56

\section{FULLY COMPLIANT AUTOCLAVE}

The DAC UNIVERSAL combination autoclave manufactured by Sirona fully complies with the Best Practice Requirements of the HTM 01-05 Memorandum.

Automated cleaning and sterilisation of handpieces by combination autoclaves is considered to be superior to manual and semi-automated methods in terms of efficiency, economy and process reliability. The DAC UNIVERSAL simultaneously cleans, lubricates and sterilises up to six handpieces in

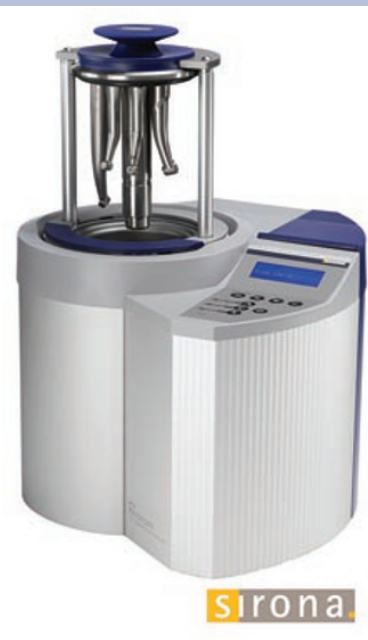

one cycle after which the instruments are ready for use within 15 minutes.

Alternatively, the instruments can be wrapped after cleaning and sterilisation and are then available for immediate use for up to 21 days. Cleaning and sterilisation can be carried out quickly which not only reduces the time spent by staff but also considerably reduces expenditure on handpieces. Moreover, the gentle cleaning and sterilisation process prevents damage to the instruments, thereby increasing their service life.

Reader response number 57 


\section{REACH INTER-PROXIMAL SPACES WITH EASE}

Scorpion ultrasonic scaler tips from Swallow Dental Supplies have a strong titanium nitride coating which provides you with a visual wear indicator to let you know when the tip needs to be replaced.

Scorpion tips are made in France from high quality stainless steel enabling the tips to be thinner and reach inter-prox- imal spaces without difficulty. They require less power input than standard and respond to the lightest pressures to reduce pain and improve comfort for your patients. Scorpion tips are compatible with Satelec, EMS, NSK, Kavo, Vista and Sirona and are available in two designs for perio and scaling.

Reader response number 58

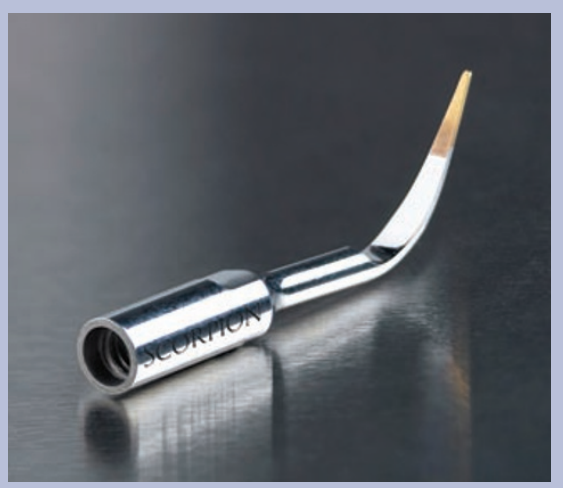

\section{ORAL HYGIENE CATALOGUE SUPPORTS CHARITY}

The Dental Directory is the UK's largest dental supplier, offering a comprehensive range of oral hygiene products, all ready for free next day delivery and at low prices. The Directory's Big Bite catalogue is a dedicated oral hygiene mini catalogue packed with special offers

\section{DENTINE IN A CAPSULE}

The revolutionary new product Biodentine, from Septodont, is the first allin-one, biocompatible and bioactive material that can be used wherever dentine is damaged, both in the crown and root.

The benefits of the product include: preservation of pulp vitality and promo- and promotions.

During November 2010 The Dental Directory will donate 5\% of all sales on oral hygiene products bought by customers from November's Big Bite catalogue to BBC Children in Need.

Reader response number 59

\section{CONTEMPORARY STYLE WITH FUNCTIONALITY}

Castellini offers a complete range of dental units, combining contemporary style with functionality.

The Castellini DUO is a result of the most highly advanced research into technology and performance. It boasts: functional instruments for high quality performance; immediate control through a userfriendly console; tension free instrument levers; and the highest safety standards and cross contamination control.

The DUO features a programmable internal decontamination cycle via the control pad for a choice of instrument tubing rinse times or the full Autosteril programme, lasting about 15 minutes. It also offers programmable instrument technology including the pre-setting of the Implantor brushless micromotor torque parameters.

Delivery, installation and a 12-month warranty are included in the price of a Castellini unit.

Reader response number 62

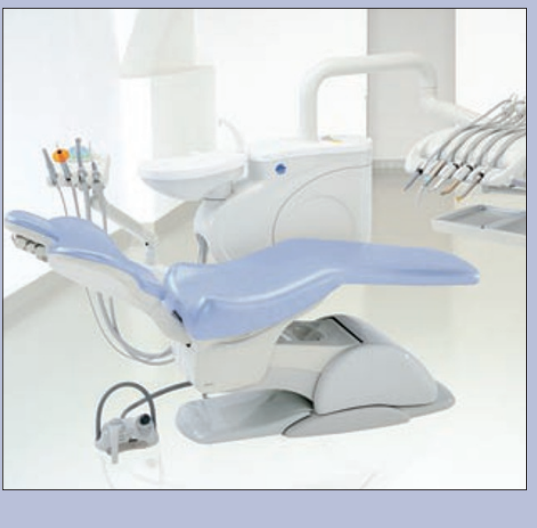




\section{INTUITIVE ENTRY-LEVEL LASER}

As the 'little brother' of the successful SIROLaser Advance, Sirona's new SIROLaser Xtend meets all dental requirements for lasers but is especially easy to operate and goes easy on the budget.

This entry-level model provides complete investment protection despite leaner technology because it can be upgraded to include all the functionality of Advance with the exception of the wireless foot control.

With a colour touchscreen, the SIROLaser Xtend features clearly structured menu navigation and self-explanatory icons for intuitive and straightforward ease of use. The seamlessly activated finger switch integrated in the handpiece makes activating the laser easy. Preset programmes ensure quick and painless treatment and a help menu offers additional information.

Practitioners can also map their own individual working style: up to 24 applications can be programmed with self-selected parameters.

Reader response number 63

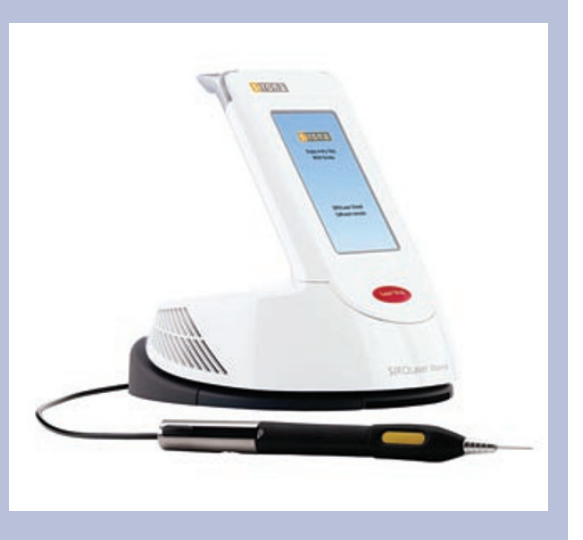

\section{ENDODONTIC HANDPIECE WITH APEX LOCATOR}

The Tri Auto ZX endodontic handpiece with built in apex locator, from Quality Endodontic Distributors Ltd (QED), has three automatic functions that significantly increase the accuracy and safety of root canal treatment.

Features include automatic start and stop, whereby the file starts rotating automatically when inserted in the canal and stops when taken out.

Auto torque reverse means that if the torque load exceeds a set limit the file automatically stops and reverses its rotation; it is designed to stop files binding. When the file tip reaches the working length set it automatically stops and reverses. Finally auto apical slow down means the motor automatically slows down as the file tip approaches the apical constriction. This enhances safety when preparing the apical region.

The unit is suitable for use with most $\mathrm{n} \mathrm{i} \mathrm{c} \mathrm{k} \mathrm{e} \mathrm{l}$ titanium rotary systems and comes complete with charger, apex locator leads and a stand.

Reader response number 64

\section{DENPLAN BRAND RECOGNITION IS HIGH}

Unique among dental payment plans, Denplan is the only brand patients can ask for by name. Research has shown that one in three adults in the UK is aware of Denplan and 54\% of those asked said that they would be willing to pay more for a nationally branded dental payment plan over a practice branded plan.
More than 6,500 Denplan member dentists nationwide treat approximately 1.8 million Denplan registered patients. Denplan also provides a range of professional services for its member dentists, including the Denplan Quality Programme, Denplan Excel accreditation programme and Denplan Training. Reader response number 65

\section{PROTECTION FROM A SILENT KILLER}

Dental Air supplies safe, compressed air systems specifically designed for dental practices, clinics and hospitals. Its range of oil-free piston and scroll compressors will help to protect your staff and patients from potentially lethal bacteria.

If your practice still relies on outdated compressor models using mineral oils to function, risks include heat, moisture and oil leaking into the compressor's chamber. This is a deadly concoction that provides the ideal breeding ground for dangerous pathogens such as E. coli and legionella pneumophila. Poorly maintained or old compressors working past their full capacity only serve to exacerbate this situation.

Valuable handpieces are seriously at risk from damage by carbon particulates produced in older systems too - costly and inconvenient to service or replace.

Reader response number 66

\section{FREE FLOSS CARDS THIS MONTH}

If you send your practice details and logo to info@dentalpracticepromotion. com or call 0208236 2940, quoting 1011BDJ by 30 November 2010, you will receive 20 practice-branded $15 \mathrm{~m}$ PTFE Executive Floss Cards for free.

Practice-branded floss cards from www.dentalpracticepromotion.com are a smart and cost-effective way to promote your practice. They are ideal for patients on the move as these neat credit card size floss packs can be dropped into a handbag, wallet or pocket, ensuring your practice name and logo is the first thing your patients see when flossing.

The professional division of MyOralHealth, www.dentalpracticepromotion. com also offers PTFE tape, interbrushes, ID brushes, toothbrushes and dental slides, all of which can be personalised with your own practice logo.

Reader response number 67

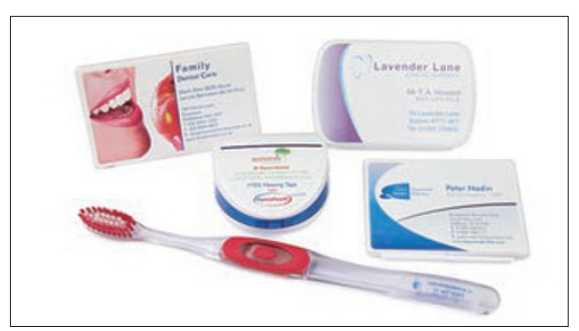

